\title{
Provider category and quality of care in the Norwegian nursing home industry
}

\author{
ASTRI DRANGE HOLE ${ }^{1, *}$ \\ ${ }^{1}$ Choice Lab, Norwegian School of Economics, Bergen, Norway
}

\begin{abstract}
This paper examines empirically if there is a link between quality of care in the Norwegian nursing home industry and exposure of the industry to competition. Exposing public care to competition implies that the responsibility for providing care services is shared between public authorities and private actors. In Norway, exposure to competition means tender competition. Suppliers bid for a contract issued by the Norwegian authorities for a limited number of years. Quality of care in an institution is the major competitive factor. The provider categories of elderly care are: 1) care provided by institutions run by municipalities, 2) care provided by institutions run by private companies, which have won a tender competition, 3) care provided by institutions run by private companies owned by private families, voluntary religious or idealistic organizations. Nurse-to-patient ratio is used as a proxy for quality of care. The regression analysis indicates a relationship between quality of care and exposure to competition. The quality of care in provider category 2 is significantly lower than in provider category 1 , but there are more variations in the quality of care in provider category 1 than in provider category 2 . We find the lowest quality of care in provider category 1 . There is also a relationship between the quality of care in an institution and the educational level of the staff, the location, the workforce, and the size of an institution. Finally, there is a relationship between the quality of care in an institution and the real and the required capacity, and the financial status in a region.
\end{abstract}

JEL classification: H42, H43, H53, H75, I1 1, I18, J14

Key words: quality of care, nursing home industry, exposure to competition, provider categories, competitive factors, privatization

\section{Introduction}

Quality is a core issue for any comprehensive analysis of the health and care services, and even more so when quality is related to the health and care of vulnerable and help-dependent elderly people. In the next few decades, the number of aged people will increase rapidly in most of the Western European countries due to increased longevity and the large cohorts born after Second World War (Borge and Haraldsvik, 2009). According to the demographic developments and statistics published by the Council of Europe in 2008, one expects that the number of people aged 65 years and more will increase by 77 percent by 2050, while the working age population - people aged 15 years to 64 years - will decline by 16 percent at the same time. This is mostly due to fertility rates below replacement level. The number of people aged 65 years and more, relative to those between 15 and 64 years, is expected to

* Correspondence to: Astri Drange Hole, Choice Lab, Norwegian School of Economics, Helleveien 30, 5045 Bergen, Norway. E-mail: astri.drange.hole@gmail.com

dx.doi.org/10.5617/njhe. 848 
double by 2050. Moreover, the life expectancy will rise by 6 years by 2050 (Council of Europe, 2008). The increase in life expectancy implying a parallel increase in the proportion of the very old ( 80 years or more) is particularly dramatic since this will increase the number of people with dementia, psychiatric and mental impairment, and complex somatic illness accordingly. Corresponding development is prevailing in the US (Reinhardt, 2000).

The debate regarding the financing of elderly care in the future started more than two decades ago in Norway. Since 1992, the Ministry of Finance in Norway has employed generational accounting. Based on the simulation results from the generational accounting model, the Ministry established a Petroleum Fund in 1996, which later became a Government Pension Fund. In 2006, the Government Pension Fund became a superstructure encompassing the Government Pension Fund Global and the Government Pension Fund Norway. The Government Pension Fund has no governing bodies or employees of its own, and is not a separate legal entity. It is the Central Bank of Norway and the National Insurance Fund, respectively, under mandates set by the Ministry of Finance that manage the Government Pension Fund Global and the Government Pension Fund Norway. Large petroleum revenues have resulted in substantial financial assets in the Government Pension Fund Global. The market value of the Fund is just over 4.714 billion NOK by 2012 - about a million NOK per capita (Norwegian Ministry of Finance, 2013). However, there is a strict policy rule that administers the Fund. In a normal year, the politicians can use four percent of the balance per January 1 each year. Hence, there is a resource scarcity, and the Norwegian Government has to prioritize between many important health and care services.

Over the last years there has been a debate regarding alternative ways of organising the elderly care sector in Norway. Should the long-term elderly care be home based or institution based? No matter how, a focal point should certainly be to provide a good quality of care. However, due to the change in the demographic structure, which is anticipated in the near future, the resources in the elderly care sector will be scarce. Hence, it will be necessary to consider efficiency matters, and the main objective should be to minimize cost whilst maintaining a good quality of care.

In Norway, it is the local authorities, which are responsible for the provision of the elderly care services. Hence, in view of the increasing proportion of elderly people, it is extremely important for the economic viability of the municipalities that resources are used efficiently in the care sector, and together with the questions "what is a good quality of care" and "how to obtain a good quality of care" these are major issues in the political debate.

To cope with a situation caused by a change in the demographic structure in the near future followed by an increased resource scarcity is also a political issue in other European countries (Lemke and Moos, 1989; Perry, 2000; Crivelli et al., 2002; Hougaard et al., 2004; Hillmer et al., 2005; Moynihan and Pandey, 2005; Farsi et al., 2008).

In the US, the nursing homes that run for profit are privately owned. Many studies based on US data have concluded that nursing homes that run for profit are associated with lower quality of care (Steffen and Nystrom, 1997; Harrington et al., 2001, 2002; O'Neill et al., 2003; Amirkhanyan et al., 2008; Amirkhanyan, 2009). However, some studies have failed to find a significant relationship between running for profit and quality of care (Castle and Shea, 1998; Weisbrod and Schlessinger, 1986). Comondore et al. (2009) have done a meta-analysis of such studies, and they suggest that, on average, not for-profit nursing homes have a trend towards higher quality of care than for-profit nursing homes, but for a large proportion of the studies, this trend is not significant.

In Norway, a certain number of the municipalities have implemented allocation policy to manage the problems caused by the increasing number of people age 80 years or more that is expected in the near future. The political authorities in these municipalities have decided to expose the care services to competition, which is a means to achieve cheaper 
services and increased focus on quality. The main purpose of this study is to examine if there is a relationship between the quality of elderly care in Norway and exposing the elderly care sector to competition. The study focuses specifically on the nursing home industry. Exposing public care to competition means that the responsibility for providing care services is shared between public authorities and private actors; the public authorities are responsible for the allocation efficiency while both private and public actors, are responsible for the cost efficiency in the nursing home they run. Hence, the politicians decide how many resources that should be allocated to the nursing home industry, while the private actors, who have won a tender competition, and public actors are responsible to run the nursing home cost efficient. There are three categories of elderly care providers. Firstly, there is public care provided by institutions run by municipalities, which are responsible for both the allocation efficiency and the cost efficiency. Secondly, care is provided by institutions run by private companies - either Norwegian or foreign - which have won the tender competition, and are responsible for the cost efficiency. Lastly, there is care provided by institutions run by private families, voluntary religious or idealistic organizations. In Norway, exposure to competition means tender competition. Suppliers bid for a contract issued by the Norwegian authorities for a limited number of years. Quality of care is the major competitive factor. Hence, this paper examines empirically if there is a link between quality of care in the Norwegian nursing home industry and exposure of the industry to competition. To my knowledge, no one has carried out an empirical analysis of this relationship for the Norwegian nursing home industry before. Hence, the current study is an attempt to address this weakness in past research.

The structure of the paper is as follows: We present the theoretical framework in section 2. In Section 3, a description of the Norwegian care sector is given. We provide details about the data we have used in the analysis in section 4 . In section 5, the analyses and the results are reported. Section 6 concludes.

\section{Theoretical framework}

The first fundamental theorem of welfare economics states that a properly working competitive economy generates a Pareto-efficient allocation of resources without any government intervention. However, it is not obvious that an efficient allocation per se is socially desirable. Fairness should also be taken into account. The second fundamental theorem of welfare economics states that of all possible Pareto-efficient outcomes, one can achieve any particular one by enacting a lump-sum income redistribution and then letting the market take over. However, in certain cases, the real-world economy is not "properly working". Hence, a market economy may not necessarily be efficient, let alone equitable. Accordingly, there is an opportunity for the government to intervene in the economy to improve economic efficiency by allocation policy and modify the distribution of income by redistribution policy. However, even though both market failure and distributional failure provide opportunities for government intervention in the economy, they do not require it. The fact that the market-generated allocation of resources is inefficient does not mean that the government is actually capable of doing better. Thus, the fundamental theorems are only helpful in identifying situations in which intervention may lead to higher social welfare.

Theoretically, there is a link between a competitive economy and social welfare, which predicts an empirical link between adopting competitive economy mechanisms in the market for care services, including the nursing home industry, and higher welfare for the recipients. Welfare theory predicts that realizing competitive market mechanisms leads to a more efficient use of the scarce resources in the sector. If the care sector, including the nursing home industry - by adopting competitive market mechanisms - is run more cost 
efficient and the freed resources are invested in the sector, there is a link between exposing the care sector to competition and higher welfare for the recipients - including better quality of care. ${ }^{1}$

The market for health- and care services is imperfect with market failures, like asymmetric information and weak consumer sovereignty (Eika, 2003; Eika, 2009). Also, the supply of health- and care services is determined by a political process in Norway, and the public services are offered at a low price. Hence, the price mechanism is not working properly. When supply increases, demand increases, and there will always be a demand surplus in the market. In addition, due to the change in the demographic structure, which one anticipates in the near future, the demand curve in the market for elderly care services - including nursing home services- will shift even further up. Accordingly, in the market for health- and care services, a competitive economy will not generate Pareto efficient allocation of resources, and there is an opportunity for the government to intervene in the economy to improve economic efficiency.

Exposure to competition implies that the responsibility for providing care services is shared between the public authorities and private actors. The public authorities specify the product and the quality requirements and provide the funding of the production of the services, while the private actors, that have won the tender competition, produce the services. Hence, the public authorities are responsible for the allocation efficiency while the private actors, that have won the tender competition, are responsible for the cost efficiency. If exposure to competition is realized as tender competition, the suppliers - both the private and the public - bid for a contract issued by the authorities for a limited number of years. Moreover, if quality of care is the major competitive factor, quality need to be defined, and measurable quality criteria need to be established accordingly. The more complex and composite a product is - like for example elderly care services - the more complicated it will be for the authorities to identify and specify the product and the quality requirements. However, to get the contract clear-cut and accurate formulated it is necessary to specify both the product and the quality requirements precisely. A contract that is not precisely specified leaves room for various interpretations. Hence, exposure to competition implies increased focus on both the product and the quality of the product in the care sector.

However, the fact that the quality of the care services is the major competitive factor in the tender competition does not imply that there is a lack of price competition. To win the contract the competitors must minimize cost whilst maintaining a good quality of care. Hence, there is both a price and a quality competition.

\section{The Norwegian care sector}

This paper focuses on the market for elderly care services, and examines the relationship between quality of care in the Norwegian nursing homes and exposing the nursing home industry to competition. In Norway, the municipalities are responsible for the provision of this care. Hence, in view of the increasing proportion of elderly people, it is extremely important for the economic viability of the municipalities that resources are used efficiently in the care sector.

\footnotetext{
${ }^{1}$ With reference to the following textbooks: Economic policy and economic profitability by Kåre Petter Hagen (2005); Public finance and public choice - analytical perspectives, by John Cullis and Philip Jones (2009); Public finance, by Harvey S. Rosen and Ted Gayer (2013); Economics of the public sector, by Joseph E. Stiglitz and Jay K. Rosengard (2015). Lectures on public economics, by Anthony B. Atkinson and Joseph E. Stiglitz (2015).
} 
In Norway, there are 888 nursing homes. 822 of these nursing homes are public and run by municipalities. Companies like Norlandia Care AS, Attendo Care AS, Adecco Helse AS, Aleris Omsorg AS and Carema Omsorg AS run 28 of the Norwegian nursing homes. Families and voluntary organizations run the rest. Hence, the respective proportions of the three categories of providers are 92.5 percent, 3.2 percent, and 4.3 percent (Statistics Norway, 2009).

In the US, the nursing homes that run for profit are privately owned. However, due to certain values materialized and institutionalized in the Norwegian welfare state, privatization of the elderly care sector is not an issue in Norway. Justice and equality are important concepts in the Norwegian society. There is also a political agreement in Norway that the authorities shall promote and encourage economic and social justice. Hence, the Norwegian welfare state produces goods and services and transfers money to the citizens based on demographic, social and economic criteria. Exposing the Norwegian nursing home industry to competition is less contrary to the principles of the Norwegian welfare state than privatization because the public authorities are responsible for the overall allocation of resources to the nursing home industry, while the private actors, that have won a tender competition, are responsible for the cost efficiency in the nursing home they run. Hence, public authorities and private actors share the responsibility for the provision of care services.

\section{Data}

We use both institutional and regional data from Statistics Norway in the analysis. However, there is no open access to the micro databases of Statistics Norway. ${ }^{2}$ Hence, due to limited data availability, we define and apply proxies in the analysis.

\subsection{Proxy for quality of care}

Quality of care in an institution is the dependent variable in the regression model that we use in the analysis, and we use nurse-to-patient ratio (NPR) as a proxy for quality of care. It is the number of trained nurses in care that is included in the proxy, while nurses with other duties in the nursing home like administration for example, are left out. In the literature, several ways to measure quality of care are identified. One approach is to use the total number of deficiencies in an institution as a quality measure. Harrington et al., 2000, 2001, and 2002 evaluate three separate groups of deficiencies: quality of care deficiencies, quality of life deficiencies, and all other deficiencies. Due to lack of Norwegian data on deficiencies, we are unable to use deficiency score as a dependent variable. However, it is well documented in the literature that a high proportion of trained nurses working in care is important in both the process and the outcome of elderly care (Grabowski and Hirth, 2003; Harrington et al., 2000). A high proportion of trained nurses working in care protects the health and ensures the safety of the residents. Hence, it seems quite reasonable to use nurseto-patient ratio as a proxy for quality of care in an institution.

However, a private company that has won the tender competition may want to maximize profit by - for example - reducing the number of nurses. If an institution minimizes cost this way, quality of care (NPR) might also be reduced. However, if so, this will not be a one to one reduction since on average 12 percent of the trained nurses in an institution are employed in the administration (Statistics Norway, 2011). Nevertheless, even with an output measure of quality of care - as for example number of various deficiencies

\footnotetext{
${ }^{2}$ The ethical guidelines regarding anonymity and professional secrecy requirements developed by the National Committee for Research Ethics in the Social Sciences and the Humanities (NESH) must be followed, and permission from the Data Inspectorate is required, and a data security agreement has been signed.
} 
in an institution - this problem might occur. Since a high proportion of nurses employed in care protects the health and ensures the safety of the residents, increasing efficiency by reducing the total number of nurses, may increase total number of deficiencies, and hence reduce the quality of care. To win the tender competition the competitors must find ways to minimize cost whilst maintaining a good quality of care. In addition, the importance of trained nurses in care for the process and outcome of elderly care is acknowledged by the Norwegian health and care authorities.

\subsection{Institutional data}

Provider category is the independent variable in the regression model, and three provider categories are applied in the analysis. 92.5 percent of the institutions are run by a municipality, which is responsible for both the allocation efficiency and the cost efficiency. 3.2 percent of the institutions are run by private companies, which have won the tender competition and are responsible for the cost efficiency. 4.3 percent of the institutions are run by voluntary organizations or families (Statistics Norway, 2009).

Education, location, workforce, and size are control variables in the regression model we use in the analysis. We measure education by total number of trained nurses per total workforce. Many studies have documented the importance of educated staff in both the process and the outcome of the care for elderly people (Grabowski and Hirth, 2003; Harrington et al, 2000). To ensure the safety and protect the health of the residents, it is important to maintain a high proportion of trained nurses in the staff. However, it can be argued that an institution who hires more physicians and less nurses will be defined as one that lowers the education level. On the other hand, few nursing homes have a physician in the workforce. Most often, there is a supervising physician visiting once or twice a week. Accordingly, the more trained nurses per total workforce in an institution, the higher is the education level.

The location of an institution is specified by centrality measures and cities. An urban location includes an urban settlement of more 50000 citizens within a 75 minutes travel time from such an urban center. There are 451 nursing homes ( 50.8 percent) in urban areas. A rural 2 location includes an urban settlement of 15 000-50 000 citizens within a 60 minutes travel time from such an urban center. There are 179 nursing homes (20.1 percent) in rural 2 areas. A rural 1 location includes an urban settlement of 5 000-15000 citizens within a 45 minutes travel time from such an urban center. There are 78 nursing homes $(8.8$ percent) in rural 1 areas. A remote location meets no requirements for travel time. There are 180 nursing homes (20.3 percent) in remote areas (Statistics Norway, 2011).

The location of an institution is also specified by city. The five biggest cities in Norway are Oslo, Bergen, Trondheim, Stavanger and Kristiansand. 12 percent of the Norwegian population lives in Oslo, and the city has 6.2 percent of the institutions. The percentages for Bergen, Trondheim, Stavanger and Kristiansand are 5.2/3.6, 3.5/2.9, 2.5/1.8 and 1.7/1.5 respectively (Statistics Norway, 2011).

Workforce is the total number of staff in an institution measured by total number of carers, trained nurses and administrators. We measure the size of an institution by number of beds.

Total number of staff, staff by category, total number of beds, and beds by institution are data from Statistics Norway 2009. The institutional variables are summarized in table A1 in the Appendix. 


\subsection{Regional data}

The municipality variables are workload, real capacity, required capacity, and financial status, and these are control variables in the regression model that we apply in the analysis. We use number of residents age $80+$ per total number of residents in a municipality as a proxy for workload. Proxies for real and required capacity are number of beds per population age $80+$ in a municipality and population age $80+$ per total population in a municipality, respectively.

Total number of residents, residents by age, residents by institution, total population, and population by age are data from Statistics Norway 2009.

We measure the financial status of a municipality by restricted cost and unrestricted income. Restricted costs are legally imposed costs spent on provision of minimum standard services and goods based on demographic, social and economic criteria. The cost index is restricted costs per citizen per national mean of restricted costs. Unrestricted income is total income minus restricted costs. The income index is income minus restricted costs plus national mean of restricted costs per citizen per national mean of unrestricted income (Langøren and Aaberge, 2011). The municipality variables are summarized in table A2 in the Appendix.

\section{Analysis and result}

Table 1 shows descriptive statistics of the quality of care for each of the three provider categories. NPR denotes nurse-to-patient-ratio, and it is a proxy for the quality of care in an institution. Public denotes institutions run by a municipality. Profit denotes institutions run by private companies - either Norwegian or foreign - which have won the tender competition. No-profit denotes institutions run by voluntary organizations or families.

Table 1: Descriptive statistics of quality of care, by provider category

\begin{tabular}{llll}
\hline NPR & Public & Profit & No-profit \\
\hline Mean & 0.300 & 0.176 & 0.263 \\
Median & 0.276 & 0.156 & 0.248 \\
St.dev. & 0.133 & 0.085 & 0.088 \\
Min & 0.019 & 0.087 & 0.127 \\
Max & 0.989 & 0.457 & 0.530 \\
$\mathrm{n}$ & 804 & 26 & 37 \\
\hline
\end{tabular}

Source: Statistics Norway 2009

Notes: NPR denotes nurse-to-patient-ratio and it is a proxy for quality of care. Public denotes institutions run by a municipality. Profit denotes institutions run by a private company - either Norwegian or foreign. Noprofit denotes institutions run by voluntary organizations or families. $n$ is number of observations. We lack descriptive statistics of NPR by provider category for 21 nursing homes.

The quality of care is on average highest (0.300) in the public institutions and lowest (0.176) in the private for-profit institutions. Results from a t-test show that this difference is statistically significant $(\mathrm{p}=0.0000)$. Results from a t-test show that the difference between public and private no-profit institutions is statistically significant $(\mathrm{p}=0.0047) .{ }^{3}$ However,

\footnotetext{
${ }^{3}$ Results from corresponding rank-sum tests show that the difference in average quality of care between public institutions and private for-profit is statistically significant $(\mathrm{p}=0.0000)$ and that the difference between public and private no-profit institutions is not statistically significant $(\mathrm{p}=0.1057)$. The $\mathrm{t}$-test is a parametric test. It is based on the assumption that the test statistic follows a normal distribution. The Wilcoxon rank-sum test is a non-parametric test, which is not based on assumptions about any specific distribution. In return, the Wilcoxon rank-sum test loses slightly in strength.
} 
there are much more variations in the public institutions. The lowest NPR is in a public institution (0.019). Standard deviation for public institutions is 0.133 , and standard deviation for profit institutions is 0.085 . Result from an F-test show that this difference in standard deviation is statistically significant $(\mathrm{p}=0.0001)$.

Table 2 shows mean and standard deviation of the quality of care for the three provider categories, by location. There are two categories of location: centrality and cities. The difference in the quality of care between public and for-profit institutions is on average smaller in Oslo than in urban Norway as a whole. Results from a t-test shows that for Oslo this difference is not statistically significant $(\mathrm{p}=0.4133) .{ }^{4}$ In other words, the difference in the quality of care between public and for-profit institutions in Oslo (0.033), which is smaller than the same difference for urban Norway as a whole (0.119), is not statistical significant.

The difference in the quality of care between public and for-profit institutions is on average larger in Bergen than in urban Norway as a whole. Results from a t-test shows that for Bergen this difference is statistically significant $(\mathrm{p}=0.0219) .{ }^{5}$ In other words, the difference in the quality of care between public and for-profit institutions in Bergen (0.131), which is larger than the same difference for urban Norway as a whole (0.119), is statistical significant. Hence, there is no typical pattern for the two biggest cities. The difference in the quality of care between public and for-profit institutions is on average smaller in Oslo and larger in Bergen than in the rest of urban Norway.

Table 2: Mean and standard deviation of quality of care, by provider category and location (centrality and city) of the institutions

\begin{tabular}{lllllll}
\hline NPR & Public & \multicolumn{3}{c}{ Profit } & \multicolumn{3}{c}{ No-profit } \\
\hline Centrality: Remote & mean & st.dev. & mean & st.dev. & mean & st.dev. \\
Centrality: Rural 1 & 0.273 & 0.114 & & & 0.225 & \\
Centrality: Rural 2 & 0.352 & 0.143 & & & 0.312 & 0.057 \\
Centrality: Urban & 0.316 & 0.136 & & & 0.256 & 0.078 \\
City: Trondheim & 0.295 & 0.136 & 0.176 & 0.084 & 0.260 & 0.093 \\
City: Bergen & 0.276 & 0.109 & & & 0.286 & 0.079 \\
City: Oslo & 0.278 & 0.046 & 0.147 & 0.044 & 0.241 & 0.091 \\
n & 0.229 & 0.092 & 0.196 & 0.105 & 0.213 & 0.045 \\
\hline
\end{tabular}

Source: Statistics Norway 2009

Notes: NPR denotes nurse-to-patient-ratio and it is a proxy for quality of care. Public denotes institutions run by a municipality. Profit denotes institutions run by private companies - ether Norwegian or foreign. No-profit denotes institutions run by voluntary organizations or families. Urban denotes a location that includes an urban settlement of more 50000 citizens within a 75 minutes travel time from such an urban center. Rural 2 denotes a location that includes an urban settlement of $15000-50000$ citizens within a 60 minutes travel time from such an urban center. Rural 1 denotes a location that includes an urban settlement of 5000-15000 citizens within a 45 minutes travel time from such an urban center. Remote denotes a location, which meets no requirements for travel time. Trondheim, Bergen, Oslo are the three biggest cities in Norway. $n$ is number of observations. We lack descriptive statistics of NPR by provider category and location for 21 nursing homes.

\footnotetext{
${ }^{4}$ Results from a rank-sum test shows that this difference is statistically significant $(\mathrm{p}=0.0754)$.

${ }^{5}$ Results from a rank-sum test shows that this difference is statistically significant $(\mathrm{p}=0.0061)$.
} 
Table 3 shows mean and standard deviation of education for the three provider categories, by the two categories of location: centrality and cities. We measure education by number of trained nurses per total workforce. For the whole country, education differs very little on average between the three provider categories. However, in Oslo and Bergen education is on average higher in for-profit than in public institutions. Also, education is on average highest in no-profit institutions in Rural 2 districts (0.347). Finally, education is on average higher in the private no-profit than in public institutions, except for Remote and Rural 1 districts.

Table 3: Mean and standard deviation of education, by provider category and location (centrality and city) of the institutions

\begin{tabular}{lllllll}
\hline Education & Public & \multicolumn{3}{c}{ Profit } & \multicolumn{3}{c}{ No-profit } \\
\hline & mean & st.dev. & mean & st.dev. & mean & st.dev. \\
\hline Centrality: Remote & 0.226 & 0.069 & & & 0.127 & \\
Centrality: Rural 1 & 0.258 & 0.093 & & & 0.241 & 0.055 \\
Centrality: Rural 2 & 0.244 & 0.086 & & & 0.347 & 0.083 \\
Centrality: Urban & 0.241 & 0.086 & 0.234 & 0.077 & 0.255 & 0.082 \\
City: Trondheim & 0.230 & 0.073 & & & 0.266 & 0.025 \\
City: Bergen & 0.236 & 0.042 & 0.283 & 0.109 & 0.243 & 0.077 \\
City: Oslo & 0.194 & 0.059 & 0.226 & 0.027 & 0.242 & 0.093 \\
Total & 0.240 & 0.084 & 0.235 & 0.077 & 0.255 & 0.083 \\
$\mathrm{n}$ & 786 & & 25 & & 38 & \\
\hline
\end{tabular}

Source: Statistics Norway 2009

Notes: Education denotes number of trained nurses per total workforce. Public denotes institutions run by a municipality. Profit denotes institutions run by private companies - either Norwegian or foreign. No-profit denotes institutions run by voluntary organizations or families. Urban denotes a location that includes an urban settlement of more 50000 citizens within a 75 minutes travel time from such an urban center. Rural 2 denotes a location that includes an urban settlement of 15 000-50 000 citizens within a 60 minutes travel time from such an urban center. Rural 1 denotes a location includes an urban settlement of 5 000-15000 citizens within a 45 minutes travel time from such an urban center. Remote denotes a location, which meets no requirements for travel time. Trondheim, Bergen, Oslo are the three biggest cities in Norway. Total denotes the whole sample. $n$ is number of observations. We lack descriptive statistics of Education by provider category and location for 39 nursing homes.

Table 4 shows mean and standard deviation of the size of an institution for the three provider categories, by the two categories of location: centrality and cities. We measure size by number of beds in an institution. As can be seen, the biggest institutions are on average for-profit institutions in in Oslo. Even so, the difference in NPR between public and forprofit institutions is on average less in Oslo than in urban Norway as a whole, and in Oslo education is on average higher in for-profit than in public institutions.

Table 5 shows an OLS (Ordinary Least Square) regression with cluster and dummies. The variables in the regression are on two levels: institution and municipality. Hence, regression with cluster is applied, and cluster refers to municipalities. To test if there is a link between the quality of care in the Norwegian nursing home industry and exposure of the industry to competition, dummies for provider category are applied. Provider 1 denotes public institutions, while provider 2 and 3 denotes for-profit and no-profit institutions, respectively. Provider 1 is the benchmark in the regression. To test if location matters for the quality of care in an institution, dummies for centrality are applied. Centrality 1 denotes remote areas, while centrality 2 and 3 denote rural areas. Centrality 4 denotes urban areas, and this is the benchmark in the regression. The quality of care is regressed on 
provider category and the control variables; education, centrality, workforce, size, workload, real and required capacity, a cost index and an income index. In section 4 of the paper, these variables are defined and in tables A1 and A2 in the Appendix, we summarize the variables.

As can be seen from table 5 the quality of care in for-profit institutions is significantly less than in public institutions. The quality of care in no-profit institutions is no different from public institutions. The higher educational level in an institution, the better quality of care. This result is significant. Centrality also matters; the location of an institution has an effect on the quality of care in the institution. The quality of care in institutions in rural areas is significantly better than the quality of care in institutions in urban areas, while the quality of care in institutions in remote areas is no different from the quality of care in institutions in urban areas. The workforce and the size of an institution also have a significant effect on the quality of care in the institution. The more staff - carers, nurses and administrators - the better quality of care, and the smaller the institution, the better quality of care. Capacity and restricted cost in the region also matter significantly. The more real capacity in the region the better quality of care in an institution, and the less required capacity in the region the better quality of care in an institution. Finally, the less restricted cost in the region the better quality of care in an institution.

Table 4: Mean and standard deviation of size, by provider category and location (centrality and city) of the institutions

\begin{tabular}{lllllll}
\hline Size & Public & \multicolumn{3}{c}{ Profit } & \multicolumn{3}{l}{ No-profit } \\
\hline Centrality: Remote & mean & st.dev. & mean & st.dev. & mean & st.dev. \\
Centrality: Rural 1 & 31 & 16 & & & 28 & \\
Centrality: Rural 2 & 36 & 21 & & & 29 & 13 \\
Centrality: Urban & 40 & 26 & & & 34 & 22 \\
City: Trondheim & 50 & 35 & 60 & 44 & 65 & 38 \\
City: Bergen & 47 & 33 & & & 42 & 19 \\
City: Oslo & 72 & 32 & 49 & 36 & 79 & 50 \\
Total & 87 & 54 & 102 & 46 & 74 & 28 \\
n & 42 & 29 & 60 & 43 & 59 & 37 \\
\hline
\end{tabular}

Source: Statistics Norway 2009

Notes: Size denotes number of beds. Public denotes institutions run by a municipality. Profit denotes institutions run by private companies - either Norwegian or foreign. No-profit denotes institutions run by voluntary organizations or families. Urban denotes a location that includes an urban settlement of more 50.000 citizens within a 75 minutes travel time from such an urban center. Rural 2 denotes a location that includes an urban settlement of 15000-50 000 citizens within a 60 minutes travel time from such an urban center. Rural 1 denotes a location includes an urban settlement of 5000-15 000 citizens within a 45 minutes travel time from such an urban center. Remote denotes a location, which meets no requirements for travel time. Trondheim, Bergen, Oslo are the three biggest cities in Norway. Total denotes the whole sample. $n$ is number of observations. 
Table 5: Regression of quality of care on provider categories and control variables

\begin{tabular}{ll}
\hline NPR & Coefficient \\
\hline Provider 2 & $-0.092^{* * *}$ \\
Provider 3 & -0.021 \\
Education & $0.147^{* *}$ \\
Centrality 1 & 0.001 \\
Centrality 2 & $0.064^{* * *}$ \\
Centrality 3 & $0.030^{* * *}$ \\
Workforce & $0.090^{* *}$ \\
Size & $-0.001^{* * *}$ \\
Workload & 0.034 \\
Real capacity & $0.125^{* * *}$ \\
Required capacity & $-1.445^{* * *}$ \\
Cost index & $-0.098^{* *}$ \\
Income index & -0.016 \\
Constant & $0.298^{* * *}$ \\
R-square & 0.272 \\
n & 763 \\
cluster & 400 \\
\hline
\end{tabular}

Note: Three stars corresponds to 1 percent significance level. Two stars corresponds to 5 percent significance level.

Notes: OLS regression with cluster and dummies. NPR denotes nurse-to-patient-ratio. NPR is a proxy for quality of care, which is the dependent variable in the regression. Provider 1 denotes public institutions. Provider 2 and Provider 3 denote for-profit and no-profit institutions, respectively. Provider 1 is also the benchmark in the regression. Education denotes number of trained nurses per total workforce. Centrality 1 denotes remote areas. Centrality 2 and 3 denote rural areas. Centrality 4 denotes urban areas, and it is the benchmark in the regression. Workforce denotes total number of staff. Size denotes total number of beds. Workload denotes number of residents age $80+$ in a municipality per total number of residents. Real capacity denotes number of beds per population age 80+ in a municipality. Required capacity denotes population age $80+$ per total population in a municipality. Cost index denotes restricted cost per citizen per national mean of restricted cost. Income index denotes income minus restricted costs plus national mean of restricted costs per citizen per national mean of unrestricted income. $n$ is number of observations. We lack information on some of the variables in the regression for 125 nursing homes. cluster refers to municipalities.

\section{Concluding remarks}

In the literature, several ways to measure the quality of care in an institution are identified. Both total number of deficiency of care in an institution and total number of deficiency of quality of life in an institution are such measures. The final choice of variables in this study has been restricted by the availability of data, and accordingly also the chosen proxy for the quality of care in an institution. However, it is well documented in the literature that a high proportion of trained nurses employed in the care process is important for the outcome of elderly care. The higher proportion of trained nurses employed in care the better protection of health and the better insurance of safety of the residents. Hence, nurse-to-patient ratios are applied as a proxy for quality of care in this study.

The regression analysis indicates a relationship between the quality of care in the Norwegian nursing homes and exposure of the nursing home industry to competition. The quality of care in institutions run by private companies - either Norwegian or foreign - is significantly lower than the quality of care in public institutions. The quality of care in 
institutions run by private families, voluntary religious or idealistic organizations is no different from the quality of care in public institutions. However, descriptive statistics indicates that there are more variations in the quality of care in the public institutions than in the institutions run by private companies, and we find the lowest quality of care in a public institution.

There is also a relationship between the quality of care and the following variables; education, location (centrality), workforce, size, real and required capacity, and financial status. The better educated staff, the better quality of care in an institution. In rural areas, the quality of care in the nursing homes is significantly better than in urban areas, while in remote and urban areas there is no difference in the quality of care in the nursing homes. The more staff in an institution, the better quality of care in the institution. Also, the quality of care is better in smaller nursing homes. The more real and the less required capacity in a region the better quality of care in an institution. Finally, the less restricted cost in a region the better quality of care in an institution.

With an aging population, the resources in the elderly care sector will soon become scarce. To run the sector more efficiently the Norwegian authorities has decided that the municipalities can implement competitive market mechanism. In doing so, the emphasis should be on minimizing cost whilst maintaining a good quality of care. However, the political debate about this issue has revealed a concern amongst the electorate that exposing the elderly care sector to competition would put more pressure on the politicians to minimizing cost than maintaining a good quality of care. This concern is reinforced by referring to the US where the health and care services are privatized and run for profit, and the profit margin of a company is of more importance than the quality of the services the company provides. However, due to certain values materialized and institutionalized in the Norwegian welfare state, privatization of the elderly care sector is not an issue in Norway. On the other hand, exposing the elderly care sector to competition is not contrary to the principles of the Norwegian welfare state in that the public authorities are responsible for the overall allocation of resources to the sector, while each private actor, who has won a tender competition, is responsible for cost efficiency in the institution. In addition, it seems that the expressed concern about the quality of elderly care services provided by private companies is not supported by the results from the current empirical study. Hence, if private companies responsible for cost efficiency run a nursing home more efficient than a municipality, there is no indication that increased efficiency comes about at the expense of good quality. In addition, to win the contract, the competitors must minimize cost whilst maintaining a good quality of care. Hence, there is both a quality and a price competition. However, the current paper has focused on the quality of care.

\section{Acknowledgements}

I would like to thank seminar participants at the Economics Department at University of Bergen; seminar participants at Uni Rokkan Centre at Uni Research Bergen; participants at The Second International "New Directions in Welfare" Conference at the OECD Headquarters in Paris, France, 2011; participants at The Third Norwegian Care Research Conference, Gjøvik 2012; participants at The 35.Annual Meeting of the Norwegian Association of Economists, University of Stavanger 2013; participants at The 36.Annual Meeting of the Norwegian Association of Economists, Norwegian Business School, Oslo 2014, and Professor Karl Rolf Pedersen, Norwegian School of Economics, for valuable comments. 


\section{References}

Amirkhanyan A.A., Kim H.J. and Lambright K.T. (2008). Does the public sector outperform the non-profit and for-profit sectors? Evidence from a national panel study on nursing home quality and access. Journal of Policy Analysis and Management, 27(2): 326-353.

Amirkhanyan A.A. (2009). Privatizing of public nursing homes: Examining the effect on quality and access. Public Administration Review, 68(4).

Atkinson A.B. and Stiglitz J.E. (2015). Lectures on public economics (Updated ed). Princeton University Press. US.

Borge L.E. and Haraldsvik M. (2009). Efficiency potential and determinants of efficiency: an analysis of the care for the elderly sector in Norway. International Tax and Public Finance, 16: 468-486.

Castle N.G. and Shea D.G. (1998). The effect of for-profit and non-for-profit facility status on quality of care for nursing homes. Research on Aging, 20(2) : 246-263.

Comondore V.R., Devereaux P.J., Zhou Q., Stone S.B., Busse J.W., Ravindran N.C., Burns K.E., Haines T., Stringer B., Cook D.J., Walter S.D., Sullivan T., Berwanger O., Bhandari M., Banglawala S., Lavis J.N., Petrisor B., Schünemann H., Walsh K., Bhatnagar N. and Guyatt G.H. (2009). Quality of care in for-profit and not-for-profit nursing homes: systematic review and meta-analysis. British Medical Journal, 339: b2732.

Council of Europe. (2008). Recent Demographic Developments in Europe 2008. Council of Europe Publishing, Strasbourg.

Crivelli L., Filippini M. and Lunati D. (2002). Regulation, Ownership and Efficiency in the Swiss Nursing Home Industry. International Journal of Health care, Finance and Economics, 2: 7997.

Cullis J. and Jones P. (2009). Public finance and public choice - analytical perspectives (3rd ed). Oxford University Press. UK.

Eika K.H. (2003). The difficult quality: Essays on human services with limited consumer sovereignty. PhD thesis. Department of Economics. Faculty of Social Sciences. University of Oslo.

Eika K.H. (2009). The challenge of obtaining quality care: Limited consumer sovereignty in Human services. Feminist Economics, 15(1): 113-137.

Farsi M., Filippini M. and Lunati D. (2008). Economics of scale and efficiency measurement in Switzerland's nursing homes. Working paper No.1. Department of Economics, University of Lugano, Italy. Department of Management, Technology and Economics, Zurich, Switzerland.

Grabowaski R.C. and Hirth A.R. (2003). Competitive spillovers across non-profit and for-profit nursing home. Journal of Health Economics, 22: 1-22.

Hagen K.P. (2005). Economic policy and economic profitability (2nd ed). (Translated title). Cappelen Akademisk. Oslo.

Harrington C., Zimmerman D., Karon S.L., Robinson J. and Beutel P. (2000). Nursing home staffing and its relationship to deficiencies. Journal of Gerontology: Psychological Sciences, 55(5): 278-287.

Harrington C., Woolhandler S., Mullan J., Carrillo H. and Himmelstein D.U. (2001). Does investor ownership of nursing homes compromise the quality of care? American Journal of Public Health, 91(9): 1452-1455.

Harrington C., Woolhandler S., Mullan J., Carrillo H. and Himmelstein D.U. (2002). Does investor ownership of nursing homes compromise the quality of care? International Journal of Health Services, (32)2: 315-325.

Hougaard J.L., Kronborg D. and Overgård C. (2004). Improvement Potential in Danish Elderly Care. Health Care Management Science, 7(3): 225-235. 
Hillmer M.P., Wodchis W.P., Gill S.S., Anderson G.M. and Rochon P.A. (2005). Nursing home profit status and quality of care: Is there any evidence of an association? Medical Care Research and Review, 62(2): 139-66.

Langøren A. and Aaberge R. (2011). Classification of Norwegian municipalities according to population size, economic workload and economic capacity. (Translated title). Statistics Norway Report No. 8.

Lemke S. and Moos R.H. (1989). Ownership and quality of care in residential facilities for the elderly. The Gerontologist, 29(2): 209-215.

Moynihan D. and Pandey S. (2005). Testing how management matters in an era of government by performance management. Journal of Public Administration Research and Theory, 15(3): 421439.

Norwegian Ministry of Finance. (2013). The Management of the Government Pension Fund in 2012. White Paper No. 27.

O'Neill C., Harrington C., Kitchener M. and Saliba D. (2003). Quality of Care in Nursing Homes: An analysis of relationships among profit, quality, and ownership. Medical Care, 12(12): 13181330.

Perry J.L. (2000). Bringing society in: Toward a theory of public service motivation. Journal of Public Administration Research and Theory, 10(2): 471-488.

Reinhardt U.W. (2000). Health Care for the Aging Baby Boom:Lessons from Abraod. Journal of Economic Perspectives, 14(2): 71-83.

Rosen H.S. and Gayer T. (2013). Public finance (10th ed). McGraw-Hill Irwin Press.

Statistics Norway. (2009). Municipal health and care statistics. Division for health statistics.

Statistics Norway. (2011). Standard measures of centrality. Division for health statistics.

Steffen T.M. and Nystrom P.C. (1997). Organizational determinants of service quality in nursing homes. Hospital and Health Service Administration, 42(2): 179-191.

Stiglitz J.E. and Rosengard J.K. (2015). Economics of the public sector (4th ed). W.W.Norton \& Company, Inc. US.

Weisbrod B.A. and Schlessinger M.A. (1986). Ownership form and behaviour in regulated markets with asymmetric information. In S. Rose-Ackerman (Ed.), The non-profit sector: Economic theory and public policy (pp. 133-155). Oxford University Press. NY.

(C) 2016 by the author(s). This article is an open access article distributed under the terms and conditions of the Creative Commons Attribution license (http://creativecommons.org/licenses/by/4.0/). 


\section{Appendix}

Table A1 displays the institutional variables, and table A2 displays the municipality variables.

\section{Table A1: Institutional variables}

\begin{tabular}{ll}
\hline Variable & Description \\
\hline Quality & NPR: Number of trained nurses in care per resident \\
Provider category 1 & Institutions run by municipalities \\
Provider category 2 & Institutions run by private companies; either Norwegian or foreign \\
Provider category 3 & Institutions run by families or voluntary organizations \\
Education & Number of trained nurses per total workforce \\
Location: Centrality & Urban; Rural 1; Rural 2; Remote \\
Location: City & Oslo, Bergen, Trondheim, Stavanger, Kristiansand \\
Workforce & Total number of staff: Administrators, carers, trained nurses \\
Size & Number of beds \\
\hline
\end{tabular}

Table A2: Municipality variables

\begin{tabular}{ll}
\hline Variable & Description \\
\hline Workload & Residents age 80+ per all residents \\
Real capacity & Number of beds per population age 80+ \\
Required capacity & Population age $80+$ per total population \\
Cost index & Restricted costs per citizen per national mean of restricted costs \\
& Income minus restricted costs plus national mean of restricted \\
Income index & costs per citizen per national mean of unrestricted income \\
\hline
\end{tabular}

